Abstracta Iranica

Revue bibliographique pour le domaine irano-aryen

Volume 24 | 2003

Comptes rendus des publications de 2001

\title{
«The Paizi of the Mongol Empire ». ZAS, 31 (2001), pp. 31-62.
}

\section{Denise Aigle}

\section{(2) OpenEdition}

10 Journals

Édition électronique

URL : http://journals.openedition.org/abstractairanica/34381

DOI : 10.4000/abstractairanica.34381

ISSN : 1961-960X

\section{Éditeur :}

CNRS (UMR 7528 Mondes iraniens et indiens), Éditions de l'IFRI

\section{Édition imprimée}

Date de publication : 15 mai 2003

ISSN : 0240-8910

\section{Référence électronique}

Denise Aigle, « «The Paizi of the Mongol Empire ». ZAS, 31 (2001), pp. 31-62. », Abstracta Iranica [En ligne], Volume 24 | 2003, document 103, mis en ligne le 05 janvier 2010, consulté le 25 septembre 2020. URL : http://journals.openedition.org/abstractairanica/34381 ; DOI : https://doi.org/10.4000/ abstractairanica.34381

Ce document a été généré automatiquement le 25 septembre 2020.

Tous droits réservés 


\section{" The Paizi of the Mongol Empire ". ZAS, 31 (2001), pp. 31-62.}

\section{Denise Aigle}

1 Dans cet article, l'auteur présente une introduction générale aux dix-huit tablettes d'autorité (paizi) confectionnées dans l'empire mongol : date et lieu de leur découverte, matériel dont elles sont fabriquées, apparence, transcription des inscriptions et reproduction photographique.

2 Après avoir présenté l'historique de la découverte de ces tablettes (entre 1846 et 2000), l'auteur les classe en trois groupes : les tablettes postales, les tablettes confectionnées pour l'exercice des fonctions officielles et les tablettes autorisant les déplacements pendant le couvre-feu.

3 Les tablettes postales (chengyi paizi) donnaient l'autorisation à celui qui détenait une telle tablette d'utiliser le yam, le réseau postal de l'État. Elles étaient rondes et portaient des inscriptions en or ou en argent.

4 Les tablettes confectionnées pour ceux qui exerçaient des fonctions officielles, surtout militaires, devaient être retournées au gouvernement central lorsque le militaire décédait ou s'il était destitué.

5 Les tablettes de couvre-feu, rondes et en cuivre, étaient utilisées pour voyager de nuit ou pour les patrouilles qui veillaient au respect du couvre-feu. L'auteur constate, d'après les inscriptions, que ce type de tablette n'était utilisé que localement; le détenteur d'une telle tablette ne pouvait utiliser le yam. Les tablettes possédaient des numéros de série, pour un meilleur contrôle de leur utilisation; elles étaient émises pour des charges spécifiques. Certaines de ces tablettes, utilisées pour voyager de nuit (yexing pai), portaient des inscriptions en plusieurs langues $\left(\mathrm{n}^{\circ} 8\right.$ en quatre langues; $\mathrm{n}^{\circ} 11$ en trois ; $\mathrm{n}^{\circ} 14$ en cinq).

6 L'intérêt majeur de cet article est de mettre à la disposition des chercheurs ces matériaux utiles pour comprendre l'histoire politique de l'empire. 
INDEX

Thèmes : 4.1. Histoire médiévale

\section{AUTEURS}

DENISE AIGLE

IFEAD - Damas 